\title{
СРЕДСТВА ИНДИВИДУАЛИЗАЦИИ ГРАЖДАН С ТОЧКИ ЗРЕНИЯ МОДЕРНИЗАЦИИ НОРМ ГРАЖДАНСКОГО ЗАКОНОДАТЕЛЬСТВА
}

\begin{abstract}
Аннотация: Автор анализирует состояние гражданского законодательства и имеющиеся научные точки зрения о средствах индивидуализации граждан, под которыми принято понимать персональные данные человека, позволяющие выделить его из общества других людей с различной степенью достоверности и которые, по мнению автора, следует классифицировать на социальные и физиологические (биометрические). Социальные средства индивидуализации граждан (имя, место жительства, электронная подпись и т.п.) создаются обществом, при этом законодатель допускает их повторяемость у разных субъектов. В то время какмногие физиологические средства основаны на оригинальных признаках, присущих только одному конкретному человеку (к примеру, узор сетчатки глаза). Сформулированы их дефиниции и показана практическая значимость каждого вида. Особое внимание уделено перспективам развития гражданского законодательства в связи с переходом на электронную форму документа, удостоверяющего личность гражданина РФ, который, по мнению автора, должен соответствовать следуюшим требованием: содержать не только социальнье, но и физиологические (биометрические) данные владельца; обладать сертифицированными средствами криптографической защитьл от подделки; быть адаптированным к использованию на широком спектре устройств и программных платформ; обеспечивать электронную систему быстрого изменения или дополнения персональных данных владельца, а также изготовления и выдачи уточненного экземпляра оригинала (при утилизации предшествующего); поддерживать юридическую значимость действий, совершаемых владельцем в процессе информационного взаимодействия с другими субъектами. По итогам проведенного исследования выявлена необходимость дополнения ГК РФ новой статьей 18.1 «Средства индивидуализаџии граждан» и предложена ее редакция. Предлагаемая статья не только позволит систематизировать имеющиеся в настоящий момент законы и иные нормативные правовые акты, регулирующие процесс использования и защиты средств индивидуализации граждан, но и одновременно официально установит деление средств индивидуализации на обычные и уникальные, что значительно облегчит применение средств индивидуализации граждан.
\end{abstract}

Abstract: The author analyzes the state of civil legislation and the existing scientific points of view about the means of citizen's individualization that represent person's identification information, and which according to the author's opinion should be classified as social and physiological (biometric). Special attention is given to the future development of civil legislation due to switching to an electronic document handling, verifying the identity of a citizen of the Russian Federation, which in author's opinion should meet the following standards: contain not only the social, but also physiological (biometric) data of the citizen; possess certified means of cryptographic protection against counterfeiting; provide an electronic system that would allow to make quick changes to the personal information of the citizen, as well as ability to produce and issue a replacement (should the original be lost). Based on the research conducted, it is evident that the need exists to amend the Civil Code of the Russian Federation with a new statute 18.1 "Means of citizen individualization".

Ключевые слова: Средства индивидуализации граждан, персональные даннье, биометрические данные человека, средства идентификации, криптографическая защита, узор сетчатки глаза, документ, удостоверяющий личность, антропометрические данные, папиллярные узоры пальцев, голос человека.

Keywords: Means of citizen individualization, personal information, biometric data of a person, means of identification, cryptographic protection, retinal pattern, identification document, anthropometric data, papillary lines of the fingers, person's voice. 
ражданское законодательство содержит довольно ограниченный перечень норм, объединенных в законы и иные нормативные правовые акты, посредством которых устанавливается (индивидуализируется) субъект правоотношений. В частности, на основании ст. 19 ГК РФ граждане обязаны приобретать и осуществлять свои права и обязанности под своим именем, которое включает фамилию и собственно имя, а также отчество, если иное не вытекает из закона или национального обычая. В случаях и в порядке, предусмотренных законом, гражданин может использовать псевдоним (вымышленное имя).

Поскольку имена многих граждан полностью (т.е. фамилия, имя и при наличии отчество) совпадают, для установления тождества каждому человеку выдается документ, удостоверяющий его личность, в котором указываются дата и место рождения, половая принадлежность, статус гражданства. Кроме того этот документ содержит информацию о месте и дате его выдачи, а также индивидуально определенный номер.

Эти индивидуализирующие средства следует признать традиционными, поскольку они используются любым цивилизованным обществом уже много лет. Тем не менее, из-за своей повторяемости, а также возможности создания их копий, содержащих ложную информацию, такие средства не могут гарантировать полную идентификацию человека. Поэтому применяют дополнительные сведения о конкретном гражданине, характеризующие его с физиологической точки зрения: антропометрические данные, зубная формула, группа крови, рентгеновские отображения грудной клетки, описание особых примет (шрамы, бородавки и т.п.).

Однако в связи с тем, что эти признаки встречаются у других людей, они не могут обеспечить абсолютную достоверность идентификации личности. Кроме того использование таких физиологических признаков для лиц, осуществляющих профессиональную деятельность в сфере рыночных отношений существенно затруднит гражданский оборот. Это одна из причин использования обществом новых и более удобных средств индивидуализации для фиксации участия конкретных субъектов в тех или иных юридически значимых действиях. В числе таковых - электронная подпись, идентификационный номер налогоплательщика и др. Эти средства индивидуализации детально регламентированы нормативными право- выми актами, а также признаны мировым сообществом и активно им применяются.

Вместе с тем инновационные технологии, позволяющие создавать практически неотличимые от оригинала копии средств индивидуализации, довольно часто используются недобросовестными лицами в целях скрыть свои идентифицирующие признаки и тем самым «уйти» от ответственности за совершенные правонарушения.

Если учесть, что ныне действующее гражданское законодательство не способно обеспечить желаемую степень защиты прав и законных интересов граждан при использовании таких средств индивидуализации, то становится очевидным, что в некоторых случаях необходимы уникальные данные, которые исключают свою повторяемость, т.е. присущи только одному лицу. И такие признаки выявлены наукой и активно применяются практикой, к примеру, каждый человек обладает с рождения отличительными признаками, которые отсутствуют у других людей (уникальные данные). В науке их называют биометрическими персональными данными. Именно эти признаки используются в качестве дополнительных средств, позволяющих с высокой степенью вероятности идентифицировать человека как субъекта гражданского оборота. В частности, на основе современных технологий можно установить тождество личности гражданина посредством выявления таких его уникальных данных, как:

- папиллярные узоры пальцев рук, ладоней, пальцев ног и подошв,

- формула крови, полученная на основе генотипоскопии,

- узор сетчатки глаза,

- голос,

- запах ${ }^{1}$

В установленных законодательством случаях применяется молекулярно-генетическая индивидуализирующая система на основе полиморфизма нуклеотидных последовательностей митохондральной ДНК и др.

Из выше представленного и далеко не полного перечня средств индивидуализации физических лиц можно сделать вполне определенный вывод: одни признаки, на основе которых формируются средства

\footnotetext{
1 Эти признаки применяют многие ведомства, см., например: «Финансовые услуги. Рекомендации по информационной безопасности. ГОСТ Р ИСО/ТО 13569-2007» (утв. Приказом Ростехрегулирования от 27.12.2007 № 514-ст)
} 
DOI: 10.7256/1811-9018.2014.11.13037

При цитировании этой статьи сноска на доі обязательна

\section{Право и политика $11(179) \cdot 2014$}

индивидуализации, присущи человеку с рождения. Такие средства индивидуализации позволяют идентифицировать личность с определенной степенью достоверности и являются физиологическими. Другие, например, паспортные данные, ИНН, электронная подпись и т.п., создаются в порядке и на условиях, установленных законодательством. Эти средства индивидуализации - соичиальные.

С учетом изложенного, средства, позволяющие с определенной степенью достоверности установить личность субъекта, совершающего юридически значимые действия, целесообразно делить на:

- социильные средства индивидуализации, под которыми предлагается понимать информацию о признаках, созданных обществом и присваемых каждому субъекту гражданского оборота, позволяющих выделить его из общества других лиц. При этом допускается встречаемость этих признаков у других субъектов, в том числе юридических лиц. Поскольку такие средства, являются результатами деятельности общества, то способы их создания, применения и охраны детально регламентированы соответствующими нормативными правовыми актами (к примеру, ИНН);

- физиологические средства индивидуализации или биометрические персональные данные (чаще их называют средства идентификации человека) присущи только физическим лицам, поскольку выявляются на основе физиологических признаков человека, обладающих, как правило, абсолютной оригинальностью, так как не повторяются у других субъектов (скажем, узор сетчатки глаза). Однако из-за сложности технологии или неэтичности их выявления, такие признаки применяют в случаях, установленных законом или иными нормативными правовыми актами.

Наиболее часто в гражданском обороте используют только социальные средства индивидуализации, так как их применение не требует особых технологий и позволяет довольно быстро установить субъекта, совершающего юридически значимые действия. Видимо поэтому во многих нормативных правовых актах, в том числе ведомственных, термин «средства индивидуализации» употребляется в широком смысле, т.е. без разделения на виды. С учетом этого факта в настоящей статье термин «средства индивидуализации» также употребляется в широком смысле, хотя в некоторых случаях, сделана специальная оговорка.

Анализ ныне действующего гражданского законодательства показал, что каждый признак или их совокупность, на основе которых создаются средства индивидуализации, фиксируется по пра- вилам, содержащимся в различных нормативных правовых актах, не объединенных в соответствующую систему. В их числе можно назвать следующие федеральные законы:

- от 3 июня 2009 г. № 103-Ф3 «О деятельности по приему платежей физических лиц, осуществляемой платежными агентами»;

- от 10 декабря 2003 г. № 173-Ф3 «О валютном регулировании и валютном контроле»;

- от 7 августа 2001 г. № 115-Ф3 «О противодействии легализации (отмыванию) доходов, полученных преступным путем, и финансированию терроризма»;

- от 15.11.1997 № 143-Ф3 «Об актах гражданского состояния»;

- от 2 декабря 1990 г. № 395-1 «О банках и банковской деятельности»².

Кроме того активно используются ведомственные нормативные правовые акты, которые нередко существенно ограничивают применение норм общего действия. К примеру, статья 160 ГК РФ допускает при совершении сделок факсимильное воспроизведение подписи. В то же время Федеральная Таможенная Служба России разрешает использовать факсимиле только при подготовке поздравительных, приветственных и других подобных документов ${ }^{3}$. Аналогичные ограничения установлены и другими ведомствами. Так, Правительство Москвы допускает использование факсимильного воспроизведения подписи только при подписании документов справочно-информационного характера: приглашений, справок, извещений и др ${ }^{4}$.

Таким образом, нормы, устанавливающие гражданско-правовые средства индивидуализации физических лиц, а также регулирующие порядок и условия их применения, содержатся в различных актах, каждый из которых имеет свою сферу действия, т.е. применяется самостоятельно, независимо от общих положений ГК РФ. Хотя цель создания и применения любого средства индивидуализации одна и она должна быть определена именно в ГК РФ, поскольку согласно ст. 3 ГК РФ нормы гражданского права, содержащиеся в других законах, должны соответствовать данному Кодексу.

\footnotetext{
${ }^{2}$ http://www.pravo.gov.ru, 22.07.2014.

3 Приказ ФТС России от 09.07.2014 № 1331 «Об утверждении Типовой инструкции по делопроизводству и работе архива в таможенных органах Российской Федерации».

4 Пункт 13.1.2.9. Постановления Правительства Москвы от 21.02.2006 N 112-ПП «О Регламенте Правительства Москвы» // http://www.mos.ru, 21.07.2014.
} 
С учетом изложенного, системное упорядочение нормативных правовых актов о средствах индивидуализации физических лиц в сфере гражданского оборота следует признать не просто актуальным, а первоочередным и уделить ему в процессе модернизации гражданского законодательства особое внимание. Отсюда следует вполне конкретный вывод: нормы, устанавливающие условия и порядок использования средств индивидуализации физических лиц, нуждаются в совершенствовании. Тем не менее, анализ вносимых в ГК РФ изменений и дополнений, осуществляемых в рамках реализации Концепции развития гражданского законодательства, показал, что нормы, регулирующие право граждан на использование средств индивидуализации в соответствии со своей волей и в своем интересе, в основном остались без должного внимания, поскольку модернизированы только статьи 19 и 20 ГК РФ о правах граждан на имя и место жительства ${ }^{5}$, а также принят новый Федеральный закон от 6 апреля 2011 г. № 63-Ф3 «Об электронной подписи», содержание которого обусловлено необходимостью устранить некоторые недостатки ранее действовавшего Федерального закона от 10.01.2002 № 1-Ф3 «Об электронной цифровой подписи» и привести российские принципы регулирования электронной подписи в соответствие с европейскими стандартами. Кроме того расширена сфера применения электронной подписи, а также учтены достижения научно-технического прогресса ${ }^{6}$.

В соответствии с данным законом, а также на основании статьи 160 ГК РФ право на имя реализуется гражданином в гражданском обороте при совершении юридически значимых действий и подписании различных документов, в том числе соглашений, односторонних сделок (завещание, доверенность и т.п.), не только посредством собственноручной подписи, но и использованием ее аналогов - электронной или факсимильной подписи. Эти аналоги подписей присоединяются к другой информации, существующей в электронной форме (подписываемой информации) или иным образом связанной с такой информацией, и используются для установления тождества лица, подписывающего информацию.

В.В. Орлова, анализируя виды средств индивидуализации, подразделяет их на внутренние и внешние.

\footnotetext{
${ }_{5}^{5}$ См.: Федеральный закон от 30.12.2012 № 302-Ф3 «О внесении изменений в главы 1, 2, 3 и 4 части первой Гражданского кодекса Российской Федерации» // http://pravo.fso.gov.ru/ips/

${ }^{6} \mathrm{http}: / /$ www.pravo.gov.ru
}

В частности, она пишет, что при внутренней индивидуализации объект выделяется из массы однородных ему путем выявления у него уже существующих характерных признаков. При внешней - объект наделяется индивидуализирующими признаками, которые созданы обществом и помогают выделить его из массы однородных 7 . В.В. Орлова справедливо полагает, что внутренняя индивидуализация наиболее предпочтительна, поскольку признаки, на которых она основана, созданы природой, являются уникальными и принадлежат человеку независимо от внешних обстоятельств и зачастую неотделимы от него.

Иного мнения придерживается В.Г. Алейниченко, поскольку, определяя средства индивидуализации, указывает только на совокупность социально-юридических признаков, характеризующих определенные черты индивидуальности человека и позволяющих с максимальной точностью конкретизировать, персонифицировать личность как субъекта гражданского права ${ }^{8}$. Из этой дефиниции следует, что физиологические отличительные признаки человека не являются средством его индивидуализации. Такая научная позиция представляется ошибочной, так как явно не соответствует объективной реальности.

Здесь уместно вспомнить, что социально-юридические признаки, отражающие индивидуальность человека, создаются не только органами публичной власти или местного самоуправления, но и частными лицами, в том числе самими гражданами или их представителями ${ }^{9}$. Скажем, перечень персональных данных, записываемых на электронные носители информации, содержащиеся в основных документах, удостоверяющих личность гражданина Российской Федерации, формируется в порядке, установленном органами государственной власти ${ }^{10}$. В то же время право ребенка на имя реализуется

\footnotetext{
7 Орлова В.В. Теория и практика индивидуализации в сфере интеллектуальной собственности // Дис. ... докт. юрид. наук. М., 2005. C. 22.

${ }^{8}$ Алейниченко В.Г. Гражданско-правовая индивидуализация физических лиц в Российской Федерации: Дис. ... канд. юрид. наук. Ростов н/Д, 2006.

${ }^{9}$ Более подробно см.: Лукашевич С.В. К вопросу об индивидуализации физического лица // «Законодательство». 2011. № 10.

${ }^{10}$ См., например: Постановление Правительства РФ от 04.03.2010 № 125 «О перечне персональных данных, записываемых на электронные носители информации, содержащиеся в основных документах, удостоверяющих личность гражданина Российской Федерации, по которым граждане Российской Федерации осуществляют выезд из Российской Федерации и въезд в Российскую Федерацию» // http://www.pravo.gov.ru, 12.02.2014.
} 


\section{Право и политика 11 (179) • 2014}

в соответствии с волей его родителей и только при отсутствии их соглашения - органами опеки и попечительства (ст. 58 Семейного кодекса РФ). Поэтому необходимо разработать и принять нормы, содержащие комплексное регулирование процесса создания и использования средств индивидуализации граждан в широком смысле, т.е. включающих как социальные, так и физиологические.

При создании такой системы средств индивидуализации граждан Российской Федерации, по моему мнению, следует руководствоваться принципами:

- идентификация граждан осуществляется безопасными для здоровья способами, прошедшими комплексную апробацию на практике;

- $\quad$ применяемая система идентификация граждан не нарушает заявленных гражданином религиозных прав и свобод;

- $\quad$ персональные данные граждан размещаются в формате, обеспечивающем комплексную безопасность от их несанкционированного использования;

- д документ, удостоверяющий личность:

- содержит социальные и биометрические данные владельца,

- снабжен сертифицированными средствами криптографической защиты от подделки,

- может использоваться на широком спектре устройств и программных платформ,

- обеспечен электронной системой быстрого изменения или дополнения персональных данных владельца, а также изготовления и выдачи уточненного экземпляра оригинала (при утилизации предшествующего);

- поддерживает юридическую значимость действий, совершаемых владельцем в процессе информационного взаимодействия с другими субъектами.

Важно, чтобы система средств индивидуализации граждан РФ была адаптирована к международным стандартам идентификации человека и внедрялась одновременно на всей территории Российской Федерации. При этом необходимо учитывать территориальные, отраслевые, национальные и иные особенности зоны обслуживания.

Очевидно, что такая работа требует глубоких научных изысканий, практической апробации полученных результатов в различных сферах общественных отношений и законодательной экспертизы с целью выявить наиболее оптимальные пути «вписывания» новых норм в уже действующую систему гражданского законодательства. Эти и многие другие проблемы, связанные с обеспечением надлежащего правового регулирования создания и использования средств индивидуализации граждан, детально известны Правительству РФ, ведомственным федеральным органам и организациям, работающим с персональными данными граждан. Поэтому для их решения принимаются соответствующие нормативные правовые акты, разрабатываются и проводятся многочисленные мероприятия. Так, Стратегия развития информационного общества в Российской Федерации (утв. Президентом РФ 7 февраля 2008 г. № Пр-212) является основой для подготовки и уточнения доктринальных, концептуальных, программных и иных документов, определяющих цели и направления деятельности органов государственной власти, а также принципы и механизмы их взаимодействия с организациями и гражданами в области развития информационного общества в Российской Федерации вообще и средств индивидуализации граждан в частности. Важность и значимость данной Стратегии определяется тем, что этот документ разработан с учетом международных норм, прошедших апробацию и получивших одобрение многих стран мира. В частности, в ней учтены основные положения Окинавской хартии глобального информационного общества ${ }^{11}$, Декларации принципов построения информационного общества (Женева, Швейцария, 2003 год), Плана действий Тунисского обязательства (Тунис, Тунисская Республика, 2005 год) и других международных документов.

На основе указанной Стратегии разработана и активно реализуется Концепция введения в Российской Федерации удостоверения личности гражданина Российской Федерации, оформляемого в виде пластиковой карты с электронным носителем информации, в качестве основного документа, удостоверяющего личность гражданина Российской Федерации на территории Российской Федерации (утв. распоряжением Правительства Российской Федерации от 19 сентя-

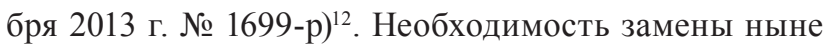
действующих паспортов ${ }^{13}$ как основного документа удостоверения личности на пластиковые карты об-

\footnotetext{
${ }^{11}$ Принята на о. Окинава 22.07.2000 // Дипломатический вестник. 2000. N 8. С. 51 - 56 (договаривающиеся стороны Великобритания, Германия (ФРГ), Италия, Канада, Россия, США, Франция и Япония).

${ }^{12} \mathrm{http} / / /$ www.pravo.gov.ru, 24.09.2013.

${ }^{13}$ В настоящее время в РФ выпускается около 14 млн. паспортов граждан Российской Федерации в почти 3000 структурных подразделениях Федеральной миграционной службы.
} 
условлена текущим уровнем развития информационных технологий и их применением в органах государственной власти и органах местного самоуправления, который создает предпосылки для введения более защищенного от подделок удостоверения личности и создания необходимой для этих целей информационно-технологической инфраструктуры. В Концепции указывается, что ее реализация позволит обеспечить:

- гарантированную государством идентификацию личности посредством как физических, так и электронных способов и средств подтверждения личности, в том числе при предоставлении государственных, муниципальных и иных услуг;

- создание комплексной системы однозначной идентификации граждан Российской Федерации на основе единого реестра удостоверений личности с использованием сквозного единого идентификатора.

Достижение этих целей планируется на 01 января 2030 года, когда прекратят свое действие «бумажные» паспорта гражданина Российской Федерации, удостоверяющего личность гражданина Российской Федерации на территории Российской Федерации.

Поставленные цели требуют решения важнейших задач, в их числе можно назвать следующие:

- разработать и внедрить инновационные технологии, позволяющие повысить степени защиты основного документа, удостоверяющего личность гражданина Российской Федерации, от подделки;

- посредством современных технических средств устранить возможности фальсификации и (или) незаконного использования основного документа, удостоверяющего личность гражданина Российской Федерации;

- гарантировать субъектам гражданского оборота идентификацию граждан, участвующих в совершении юридически значимых действий, в том числе при предоставлении государственных, муниципальных и иных услуг;

- $\quad$ расширить перечень сведений о гражданах Российской Федерации, размещенных в информационных системах, и повысить их достоверность;

- $\quad$ упростить регистрацию граждан на территории РФ по месту их пребывания и на ее основе сфор- мировать комплексную систему учета населения Российской Федерации.

Решение этих и многих других (сопутствующих) задач, несомненно, потребует довольно длительного времени. Однако уже сейчас в дополнение к тем мероприятиям, которые проводятся, необходимо главу 3. Граждане (физические лица) ГК РФ дополнить статьей 18.1. «Средства индивидуализации гражданина», диспозицию которой изложить в следующей редакции:

«1. Гражданин совершает юридически значимые действия, используя документ, удостоверяющий его личность, установленного образца и содержащий персональные данные владельца, перечень которых официально установлен (средства индивидуализации).

2. Средства индивидуализации гражданина, отраженные в документе, удостоверяющем его личность, включают в себя официально установленные сведения о его имени, месте жительства, а также иную информацию о признаках, присущих данному лицу. Допускается встречаемость таких же признаков у других лиц.

3. Уникальные средства индивидуализации гражданина, т.е. присущие только конкретному физическому лицу, выявленные на основе физиологических признаков человека (персональные биометрические данные), применяют в случаях, установленных законом или иными нормативными правовыми актами.

4. Документ, удостоверяющий личность гражданина Российской Федерации, может содержать уникальные средства индивидуализации владельца.»

Внесение данной статьи в ГК РФ не только позволит систематизировать имеющиеся в настоящий момент законы и иные нормативные правовые акты, регулирующие процесс использования и защиты средств индивидуализации граждан, т.е. послужит тем основанием, в котором определены основные начала права граждан РФ на средства своей индивидуализации, но и одновременно официально установит деление средств индивидуализации на социальные и физиологические, в том числе уникальные. Думаю, что такая новелла ГК РФ значительно продвинет процесс модернизации гражданского законодательства в сфере усиления защиты прав и законных интересов граждан РФ.

\section{Библиография:}

1. Гражданский кодекс Российской Федерации от 26 января 1996 г. N 14-Ф3 // Собрание законодательства Российской Федерации от 29 января 1996 г. N 5 ст. 410 (с изм. и доп., вступ. в силу с 01.09.2014)

2. Федеральный закон от 30.12.2012 № 302-Ф3 «О внесении изменений в главы 1, 2, 3 и 4 части первой Гражданского кодекса Российской Федерации» // http://pravo.fso.gov.ru/ips/, 04.03.2013;

3. Федеральный закон от 6 апреля 2011 г. № 63-Ф3 «Об электронной подписи» // http://www.pravo.gov.ru, 30.06.2014; 
DOI: 10.7256/1811-9018.2014.11.13037

При цитировании этой статьи сноска на dоі обязательна

\section{Право и политика $11(179) \cdot 2014$}

4. Федеральный закон от 3 июня 2009 г. № 103-Ф3 «О деятельности по приему платежей физических лиц, осуществляемой платежными агентами»;

5. Федеральный закон от 10 декабря 2003 г. № 173-Ф3 «О валютном регулировании и валютном контроле»// http://www. pravo.gov.ru, 22.07.2014;

6. Федеральный закон от 7 августа 2001 г. № 115-Ф3 «О противодействии легализации (отмыванию) доходов, полученных преступным путем, и финансированию терроризма»// http://www.pravo.gov.ru, 22.07.2014;

7. Федеральный закон от 15.11.1997 № 143-Ф3 «Об актах гражданского состояния» // http://www.pravo.gov.ru, 24.06.2014;

8. Федеральный закон от 2 декабря 1990 г. № 395-1 «О банках и банковской деятельности»// http://www.pravo.gov.ru, 22.07.2014;

9. Постановление Правительства РФ от 04.03.2010 № 125 «О перечне персональных данных, записываемых на электронные носители информации, содержащиеся в основных документах, удостоверяющих личность гражданина Российской Федерации, по которым граждане Российской Федерации осуществляют выезд из Российской Федерации и въезд в Российскую Федерацию» // http://www.pravo.gov.ru, 12.02.2014;

10. Стратегия развития информационного общества в Российской Федерации (утв. Президентом РФ 7 февраля 2008 г. № Пр-212) // «Российская газета». 16.02.2008, № 34.

11. Концепция введения в Российской Федерации удостоверения личности гражданина Российской Федерации, оформляемого в виде пластиковой карты с электронным носителем информации, в качестве основного документа, удостоверяющего личность гражданина Российской Федерации на территории Российской Федерации (утв. распоряжением Правительства Российской Федерации от 19 сентября 2013 г. № 1699-p) // http://www.pravo.gov.ru, 24.09.2013.

12. Алейниченко В.Г. Гражданско-правовая индивидуализация физических лиц в Российской Федерации: Дис. ... канд. юрид. наук. Ростов н/Д, 2006.

13. Лукашевич С.В. К вопросу об индивидуализации физического лица // «Законодательство». 2011. № 10.

14. Орлова В.В. Теория и практика индивидуализации в сфере интеллектуальной собственности // Дис. ... докт. юрид. наук. M., 2005.

15. К. В. Лиджеева Средства индивидуализации и их правовая охрана // Право и политика. - 2012. - 4. - С. $780-787$.

16. Астанин В.В. Об эффективных механизмах взаимодействия государства с гражданским обществом в сфере противодействия коррупции. // Административное и муниципальное право. - 2011. - 4. - С. 5-8.

17. А. Л. Ефимов Программные документы и их роль в формировании российского законодательства // Политика и Общество. $-2011 .-6 .-$ С. $38-44$.

18. К. В. Лиджеева Средства индивидуализации и их правовая охрана // Право и политика. - 2012. - 4. - С. 780 - 787.

19. В.Н. Шеломенцев Формирование законодательства о гражданском обществе в России на рубеже XVIII--XIX веков // Политика и Общество. - 2013. - 1. - C. 4 - 16. DOI: 10.7256/1812-8696.2013.01.1.

20. Астанин В.В. Об эффективных механизмах взаимодействия государства с гражданским обществом в сфере противодействия коррупции. // Административное и муниципальное право. - 2011. - 4. - С. 5 - 8.

\section{References (transliterated):}

1. Aleinichenko V.G. Grazhdansko-pravovaya individualizatsiya fizicheskikh lits v Rossiiskoi Federatsii: Dis. ... kand. yurid. nauk. Rostov n/D, 2006.

2. Lukashevich S.V. K voprosu ob individualizatsii fizicheskogo litsa // “Zakonodatel'stvo”. 2011. № 10.

3. Orlova V.V. Teoriya i praktika individualizatsii v sfere intellektual'noi sobstvennosti // Dis. ... dokt. yurid. nauk. M., 2005.

4. K. V. Lidzheeva Sredstva individualizatsii i ikh pravovaya okhrana // Pravo i politika. - 2012. - 4. - C. $780-787$.

5. Astanin V.V. Ob effektivnykh mekhanizmakh vzaimodeistviya gosudarstva s grazhdanskim obshchestvom v sfere protivodeistviya korruptsii. // Administrativnoe i munitsipal'noe pravo. - 2011. - 4. - C. 5-8.

6. A. L. Efimov Programmnye dokumenty i ikh rol' v formirovanii rossiiskogo zakonodatel'stva // Politika i Obshchestvo. - 2011. $-6 .-$ C. $38-44$.

7. K. V. Lidzheeva Sredstva individualizatsii i ikh pravovaya okhrana // Pravo i politika. - 2012. - 4. - C. $780-787$.

8. V.N. Shelomentsev Formirovanie zakonodatel'stva o grazhdanskom obshchestve v Rossii na rubezhe XVIII--XIX vekov // Politika i Obshchestvo. - 2013. - 1. - C. 4 - 16. DOI: 10.7256/1812-8696.2013.01.1.

9. Astanin V.V. Ob effektivnykh mekhanizmakh vzaimodeistviya gosudarstva s grazhdanskim obshchestvom v sfere protivodeistviya korruptsii. // Administrativnoe i munitsipal'noe pravo. - 2011. - 4. - C. 5 - 8. 